\title{
Evaluasi Penerapan Standar Operasional Prosedur Housekeeping Department Dalam Penyediaan Bath Towel di The Acacia Hotel Jakarta
}

\author{
Evaluation of The Implementation Of Housekeeping Department \\ Operational Standards In The Provision Of Bath Towel In The Acacia \\ Hotel Jakarta
}

\author{
Fristi Bellia Annishia $^{1)}$ Riswanto $^{2)}$ \\ 1) Akademi Pariwisata Pertiwi Bogor \\ ${ }^{2)}$ Akademi Pariwisata Pertiwi Bogor
}

09 Mei 2020

\begin{abstract}
In generally the purpose of visiting guests mostly to stay. Along with the number of the hotel that stand it must be a competitor, then the room service and all the fittings should be considered and prepared as possible. Completeness in the guest rooms are also a necessity at the time of stay, one of which is bath towel. However, through research that has done, seen a problem arising from the very lack of stock, par stock of bath towel owned by The Acacia Hotel Jakarta. This resulted in complaints on guests caused by the absence of bath towel in the hotel room. One of the most important departments in maintaining and providing satisfactory service to guests, namely Housekeeping. Housekeeping Department divided into several parts one of which is a room section that has the task to maintain cleanliness, safety, comfort and completeness of guest rooms. So the role of housekeeping is very important in fulfilling the completeness of facilities in each room which one of them is the completeness of bath towel in the hotel room to achieve the level of satisfaction of guests who stay.
\end{abstract}

Keywords: Housekeeping Department, Par stock, Bath towel

\begin{abstract}
ABSTRAK
Pada umumnya tujuan tamu yang berkunjung kebanyakan untuk menginap. Seiring banyaknya hotel yang berdiri yang tentunya menjadi pesaing, maka pelayanan kamar serta segala kelengkapannya harus diperhatikan dan dipersiapkan sebaik mungkin. Kelengkapan pada kamar tamu yang juga menjadi kebutuhan pada saat menginap, salah satunya adalah bath towel. Akan tetapi melalui penelitian yang telah dilakukan, terlihat adanya masalah yang timbul akibat sangat kurangnya persediaanpar stockbath towel yang dimiliki Hotel The Acacia Jakarta. Hal ini mengakibatkan timbulnya keluhan pada tamu yang disebabkan karena tidak terdapatnya bath towel di kamar hotel. Salah satu departemen yang paling penting dalam mempertahankan dan memberikan pelayanan yang memuaskan bagi para tamu, adalah Housekeeping. Housekeeping Department dibagi menjadi beberapa bagian salah satunya adalah room section yang mempunyai tugas untuk menjaga kebersihan, keamanan, kenyamanan dan kelengkapan kamar tamu.Dengan demikian peranan housekeeping sangatlah penting dalam memenuhi kelengkapan fasilitas di setiap kamar yang salah satunya yaitu kelengkapan bath towel di kamar hotel guna mencapai tingkat kepuasan tamu yang menginap.
\end{abstract}

Kata Kunci: Departemen Tata Graha, handuk, linen, persediaan 


\section{PENDAHULUAN}

Industri pariwisata di Indonesia sudah berkembang cukup pesat dengan melihat kunjungan wisatawan domestic maupun mancanegara ke berbagai daerah Indonesia yang terus meningkat dari tahun ke tahun. Sehingga sarana pendukung pariwisata seperti hotel juga bertambah banyak. Perkembangan dunia perhotelan semakin pesat, sehingga berpengaruh terhadap banyak berdirinya Hotel pada kota-kota besar di Indonesia, baik di kelas melati maupun kelas berbintang. Hal ini juga terjadi di kota Jakarta, sebagai Ibu Kota Negara Indonesia yang pariwisatanya juga telah berkembang, dan diikuti dengan banyak berdirinya hotel-hotel, salah satunya The Acacia Hotel Jakarta.

Hotel The Acacia Jakarta ini banyak diminati oleh para tamu ,karena letaknya yang sangat strategis di Jantung Kota Jakarta dekat dengan Central Business District of Sudirman, Thamrin, Kuningan, begitupun dengan kantorkantor pemerintahan utama, pusat perbelanjaan, dan tempat rekreasi. Dengan demikian tingkat hunian kamarpun terhitung cukup tinggi, oleh karena itu perlu diperhatikan, semakin banyak hotel yang didirikan semakin banyak pula hotel-hotel yang menjadi pesaing. Hal ini tentunya mengharuskan Hotel The Acacia Jakarta untuk memperhatikan, mempertahankan, dan meningkatkan pelayanan yang ada. Dengan meningkatnya pelayanan di Hotel The Acacia Jakarta tentunya akan membuat hotel ini tetap menjadi pilihan untuk tamu yang datang atau menginap dan mendapatkan kepuasan terhadap segala pelayanan yang diberikan.

Seiring banyaknya hotel yang berdiri yang tentunya menjadi pesaing, maka pelayanan kamar serta segala kelengkapannya harus diperhatikan dan dipersiapkan sebaik mungkin. Kelengkapan pada kamar tamu yang juga menjadi kebutuhan pada saat menginap, salah satunya adalah bath towel. Akan tetapi melalui observasi yang telah dilakukan, terlihat adanya masalah yang timbul akibat sangat kurangnya persediaan bath towel yang dimiliki Hotel The Acacia Jakarta. Hal ini mengakibatkan timbulnya keluhan pada tamu yang disebabkan karena tidak terdapatnya bath towel di kamar hotel.

Dalam hal ini penerapan Standard Operasional
Prosedur yang baik dan peranan sumber daya manusia di departemen Housekeeping sangatlah penting, karena mereka adalah orang - orang yang menjalankan Standard Operasional Prosedur pembersihan serta kelengkapan pada setiap kamar hotel. Sumber daya manusia di departemen housekeeping tersebut meliputi para Room Attendant, Linen Attendant, Supervisor, Executive Housekeeper, dan bagian lain yang terkait dalam lingkup organisasi hotel.

Untuk menunjang kelancaran operasional, menurut Rumekso (2007, dalam Suryanata 2016:10) suatu hotel harus melengkapi seluruh item linen terutama room linen dengan persediiaan linen ideal (ideal parstock) adalah 5 par dan minimal 3 par dengan asumsi:

\section{1 par linen terpasang}

1. 1 par linen di laundry (kotor)

2. 1 par linen siap pakai

Salah satu departemen yang paling penting dalam mempertahankan dan memberikan pelayanan yang memuaskan bagi para tamu, yakni Housekeeping. Housekeeping Department dibagi menjadi beberapa bagian salah satunya adalah room section yang mempunyai tugas untuk menjaga kebersihan, keamanan, kenyamanan dan kelengkapan kamar tamu. Tugas tersebut dilaksanakan oleh salah satu petugas di room section yaitu Room Attendant.Dengan demikian peranan housekeeping sangatlah penting dalam memenuhi kelengkapan fasilitas di setiap kamar yang salah satunya yaitu kelengkapan bath towel di kamar hotel guna mencapai tingkat kepuasan tamu yang menginap.

Berdasarkan uraian dalam latar belakang masalah tersebut di atas, maka permasalahan yang terkait dengan penelitian ini dapat diidentifikasi sebagai berikut:

1. Bagaimana evaluasi penerapan SOP Housekeeping Department dalam penyediaan bath towel di The Acacia Hotel?

2. Bagaimana solusi yang dilakukan oleh The Acacia Hotel dalam mengatasi kurangnya persediaan bath towel?

\section{LANDASAN TEORI}

Standar Operasional Prosedur (SOP) adalah dokumen yang berkaitan dengan 
prosedur yang dilakukan secara kronologis untuk menyelesaikan suatu pekerjaan yang bertujuan untuk memperoleh hasil kerja yang paling efektif dari para pekerja dengan biaya yang serendah-rendahnya. SOP biasanya terdiri dari manfaat, kapan dibuat atau direvisi, metode penulisan prosedur, serta dilengkapi oleh bagan flowchart dibagian akhir (Laksmi, 2008:52). Setiap perusahaan apapun bisnis maupun, usahanya wajib memiliki Standartd Operating Procedures (SOP) karena merupakan guideline bagaimana proses sebuah fungsi kerja ditegakkan. Keberadaannya dapat menjadi rujukan apabila ditemukan sesuatu tidak maksimal dalam hal ini tidak efektif dan efisien.

\section{a. Unsur-unsur SOP}

Menurut Tambunan (2008, dalam Pahlevi 2014:20) unsur-unsur Standard Operating Procedures (SOP) adalah tujuan, kebijakan, petunjuk operasional, pihak yang terlibat, formulir, masukan, proses, laporan, validasi, dan kontrol. Tujuan merupakan unsur pertama yang dibutuhkan dalam pembuatan SOP pada perusahaan, ini dikarenakan agar pembuatan SOP memiliki arah yang sama dengan organisasi. Pernyataan tujuan dalam pembuatan SOP tidak terlepas dari adanya kebijakan sebagai pedoman dan rujukan yang harus ditaati dalam pengambilan keputusan dan pelaksanaan kegiatan. Maka itu SOP perlu di lengkapi dengan pernyataan kebijakan-kebijakan yang terkait, yang mendukung pelaksanaan prosedur secara efektif dan efisien.

Pada unsur petunjuk operasional di dalam pembuatan SOP, ini menjelaskan tentang SOP yang telah dibuat melainkan tata cara pengguna dalam membaca pedoman atau panduan prosedur operasional secara benar. Petunjuk operasional ini sangat penting karena utuk mengarahkan pengguna dalam memahami berbagai bentuk tampilan dan simbol-simbol yang digunakan dalam prosedur yang digunakan. Suatu prosedur yang dibuat akan melibatkan orang-orang atau pihak-pihak sebagai pelaksananya dengan kapasitas dan tanggung jawab yang berbeda baik dalam hal dimensi keputusan, pelaksaan, ataupun keduaduanya. Maka penjelasan tentang pihak yang terlibat perlu dijelaskan secara rinci agar para pengguna memahami tentang siapa-siapa dan fungsi-fungsi yang terlibat dalam prosedur (Tambunan, 2008 dalam Pahlevi, 2014:21).

\section{b. Tujuan SOP}

Menurut Suryono (2011, dalam Pahlevi, 2014:23) tujuan SOP adalah menyederhanakan pekerjaan kita supaya hanya berfokus pada intinya, tetapi cepat dan tepat, namun secara umum SOP adalah sebagai berikut:

1) Menciptakan komitmen mengenai apa yang dikerjakan oleh satuan unit kerja perusahaan untuk mewujudkan good corporate governance.

2) Agar petugas/pegawai menjaga konsistensi dan tingkat kerja petugas/pegawai atau tim dalam organisasi atau unit kerja.

3) Agar mengetahui dengan jelas peran dan fungsi tiap-tiap posisi dalam organisasi.

4) Memperjelas alur tugas, wewenang dan tanggung jawab dari petugas/pegawai terkait.

5) Melindungi organisasi/unit kerja dan petugas/pegawai dari malpraktek atau kesalahan administrasi lainnya.

6) Untuk menghindari kegagalan/kesalahan, keraguan, duplikasi dan inefiensi.

\section{c. Manfaat Teknis SOP}

Menurut Tambunan (2008, dalam Pahlevi, 2014:24) suatu organisasi harus menjalankan kegitan-kegiatan tersebut secara efektif dan efisien, agar daya saing dan kualitas layanan meningkat. Cara paling tepat untuk mewujudkan efektifitas dan efisiensi kegiatan, salah satunya adalah dengan menerapkan secara menyeluruh prosedur-prosedur operasional atau SOP, dengan manfaatmanfaat teknis yang jelas.

Secara rinci, manfaat-manfaat yang diperoleh oleh organisasi dengan menyusun dan menerapkan Standard Operating Procedures (SOP) adalah sebagai berikut:

1) Menjamin adanya standarisasi kebijakan

2) Menjamin adanya standarisasi pelaksanaan setiap Standard Operating Procedures (SOP).

3) Menjamin adanya standarisasi penggunaan dan distribusi formulir, blanko, dan dokumen dalam prosedur.

4) Menjamin adanya standarisasi system administrasi (termasuk kegiatan penyimpanan arsip dan system dokumentasi).

5) Menjamin adanya standarisasi validasi.

6) Menjamin adanya standarisasi pelaporan.

7) Menjamin adanya standarisasi kontrol.

8) Menjamin adanya standarisasi pelaksanaan evaluasi dan penilaian kegiatan organisasi/perusahaan. 
9) Menjamin adanya standarisasi pelayanan dan tanggapan kepada pihak luar organisasi.

10) Menjamin adanya standarisasi keterpaduan dan keterkaitan di antara satu prosedur dengan prosedur operasional lainnya dalam konteks dan kerangka tujuan organisasi.

11) Memastikan adanya acuan formal bagi anggota organisasi untuk menjalankan kewajiban di dalam Standard Operating Procedures (SOP).

\section{d. Tugas dan Tanggung Jawab Housekeeping Departement Secara Umum}

Tugas dan tanggung jawab sangat berkaitan erat demi menciptakan kinerja yang baik, sehingga pekerjaan berjalan lancar dan sesuai tujuan yaitu memberikan pelayanan yang memuaskan untuk tamu dan tamu merasa puas akan pelayanan yang diberikan.

Tugas Housekeeping menurut Darsono (1992, dalam Safitri, 2016:7) meliputi:

1) Memberikan pelayanan kepada tamu hotel yang menginap dengan sebaik-baiknya agar tamu merasa puas pada saat menginap di hotel.

2) Menciptakan suasana hotel bersih, nyaman, aman dan menarik.

3) Membangun komunikasi baik antar semua department.

4) Bertanggung jawab atas pemeliharaan, kerapihan, dan kenyamanan, kebersihan seluruh area hotel baik kamar ataupun public area.

5) Memilih dan menentukan cleaning equipment dan cleaning material sesuai dengan kebutuhan.

6) Melaksanakan pelayanan lain seperti, melaporkan barang-barang tamu yang tertinggal di kamar atau Lost and Found kepada Lost and Prevention Department dan melakukan pelayanan lain yang tidak bisa dilakukan oleh department lainnya di hotel.

Sedangkan tanggung jawab housekeeping meliputi:

1) Guest Room and Guest Toilet,

2) Corridor,

3) Office,

4) Banquet and Restaurant,

5) Employee Locker and Employee Toilet,

6) In out door garden,

7) Swimming Pool,

8) Laundry and

9) Guest Lift and Employee Lift

\section{e. Laundry sebagai bagian dari Departemen} Housekeeping

Berdasarkan tugas dan tanggung jawabnya, bagian laundry mempunyai pengaruh yang sangat besar dalam mendukung operasional pelayanan hotel kepada tamu, pelayanan ini meliputi hal-hal berikut:

1) Pencucian linen yang dipergunakan di food\&beverage, yaitu tablecloth, napkin, tablemat

2) Pencucian linen yang dipergunakan di kamar, yaitu pillowcase, blanket, towel, dan bed cover.

3) Pencucian seragam semua karyawan yang meliputi jas, celana, baju, kemeja, celemek, dan lainnya.

4) Cucian tamu hotel (guest laundry), yaitu pakaian-pakaian tamu yang menginap di hotel. Pelayanan ini meliputi:
a) Dry cleaning
b) Laundry
c) Pressing

5) One side laundry counter, yaitu pelayanan pencucian pakaian, linen dan lainnya yang berasal dari luar hotel.

Jika dilihat dari bentuk pelayanan laundry, keberadaan seksi-seksi di laundry sangatlah penting karena sangat mendukung operasional bagian binatu. Dengan adanya seksi-seksi di laundry ini maka pekerjaan dapat dibagi sesuai dengan seksi masing-masing sehingga pekerjaan dapat diselesaikan dengan tepat dan pelaksanaan tugas itu sendiri menjadi lebih efektif.

Seksi-seksi yang ada pada bagian laundry adalah sebagai berikut:

1) Seksi binatu (Laundry Office): Seksi ini bertanggung jawab atas kelancaran tugas dan administrasi di laundry office

2) Seksi Counter: Seksi ini bertanggung jawab atas kelancaran penerimaan dan pengembalian cucian bersih kepada tamu luar hotel yang mencuci (outside laundry) counter.

3) Deliver Valet (Pengambil Cucian): Deliver adalah petugas yang bertanggung jawab pengambilan cucian kotor ke laundry dan pengiriman cucian bersih ke kamar tamu. Semua cucian yang diantar harus sesuai dengan laundry list (daftar laundry)

4) Order Taker (Pengambilan Pesanan): Petugas ini bertanggung jawab atas order permintaan pencucian dari tamu melalui telepon. Setelah order taker menerima permintaan dari tamu dan untuk selanjutnya 
dicatat pada order taker book lalu memberitahukan kepada valet agar mengambil cucian tersebut.

5) Checker (Pengecek): Petugas ini bertangguung awab memeriksa jumlah dan jenis cucian agar sesuai dengan laundry list.

6) Marker (Penyortir): Seksi ini bertanggung jawab memberi tanda/kode pada cucian agar cucian tersebut mudah penanganannya saat pengembalian serta tidak terjadi kesalahan.

7) Washer (Pencuci): Seksi ini bertangguung jawab atas pencucian pakaian yang dilakukan secara laundry, yaitu menggunakan air dan obat pencuci.

8) Dry Cleaning (Pencucian secara kering): Seksi ini bertanggung jawab atas pencucian secara dry cleaning.

9) Finisher (Penyelesaian): Seksi yang bertanggung jawab menyelesaikan pengepresan dan penyetrikaan pakaian tamu setelah selesai dikeringkan. Bila ada cucian yang belum bersih dan belum sempurna maka akan dikembalikan oleh seksi finisher untuk dicuci ulang.

10) Ironer (Penyetrika linen-linen): Seksi yang bertanggung jawab pada penyetrikaan cucian yang berbentuk lembaran, seperti sprei, sarung bantal, taplak meja, dan serbet.

11) Presser (Penyetrika): Seksi yang bertanggung jawab pada penyetrikaan cucian yang mengguunakan setrika maupun setrika press.

\section{f. Peralatan dan Chemical pada Laundry}

Untuk dapat melaksanakan tugasnya dengan baik, bagian laundry memerlukan mesin-mesin yang berhubungan dengan pencucian, mesin-mesin itu adalah sebagai berikut:

1) Marker Machine (Mesin Pemberi Tanda): Mesin yang bekerja secara otomatis, member tanda pada cucian tamu. Mesin ini dapat mencetak nomor kamar, noomor urup pada pita kecil dan menempelkannya pada cucian tamu. Tanda ini untuk menghindari cucian milik tamu atau cucian tertukar.

2) Washing Machine (Mesin Cuci): Mesin untuk mencuci pakaian dan linen kotor. Pada proses pencucian diguunakan obat pembersih yaitu sabun dan detergjen. Mesin inii secara otomatis menghilangkan kotoran dan membilas dengan air hingga bersih.

3) Extractor Machine (Mesin Pemeras Cucian): Mesin ini bekerja secara otomatis memeras cucian yang selesai dicuci. Cucian itu menjadi lembab, seingga mudah dalam proses pengeringan di mesin tumbler (pemeras). Petugas yang menjalankan mesin pemeras ccucian ini harus menutup pintunya. Sebelumnya harus ditutup kain penutup (terpal) agar cucian yang diperas tidak keluar.

4) Tumbler Machine (Mesin Pengering): Mesin ini bekerja secara otomatis mengeringkan cucian-cucian yang sudah diperas.

5) Pressing (Setrika Press): Mesin ini berguna untuk memperhalus dan merapikan cucian.

6) Flat Roll Ironer (Setrika khusus linen-linen berbentuk lembaran): Mesin ini bekerja secara otomatis menyetrika linen-linen hotel, yang merupakan lembaran-lembaran. Misalnya sheet (sprei), pillowcase (sarung bantal), taplak meja, napkin (kain serbet).

7) Ironer (Strika tangan): Mesin setrika tangan yang dipergunakan seperti setrika biasa. Mesin ini dihubungkan dengan aliran uap panas sehingga sangat praktis dipakai.

Dalam pencucian terkadang diperlukan obat pembersih tertentu untuk menolong dalam membersihkan pakaian, misalnya pakaian yang terkena noda tertentu. Berikut penjabaran untuk setiap obat-obat pembersih (Chemicals) yang diperlukan di atas yaitu:

1) Liquid Soap (Sabun cair): Obat pembersih berupa sabun cair, penggunaannya disesuaikan dengan jumlah cucian.

2) Bleaching (Pemutih): Obat pembersih/ pemutih yang digunakan terutama untuk linen putih agar kelihatan lebih cemerlang.

3) Deterjen: Obat pembersiih berupa sabun bubuk. Penggunaannya disesuaikan dengan jumlah cucian.

4) Softening (pelembuut): Obat berupa cairan untuuk membuuat handuk menadi lembut setelah selesai dicuci.

5) Souring (Penetral): Obat berupa cairan untuk membuat penetral dalam proses pencucian linen.

\section{g. Proses Laundry dan Linen Storage}

Sebelum masuk kedalam tahap-tahap atau proses $h l=$, kita pahami terlebih dahulu pengertian proses pencucian itu sendiri yaitu, suatu proses pembersihan benda dengan jalan mengeluarkan atau melepaskan partikelpartikel atau pengotor yang bersangkutan. Kemudian proses pencucian itu sendiri memiliki tujuan yaitu untuk:

1) Menghilangkkan noda dan kotoran yang melekat pada tekstil 
2) Menjaga agar tekstil terbebas dari kuman

3) Menjaga tekstil agar tetap cemerlang

4) Menjaga agar sifat asli dari tekstil tetap bertahan, misalnya: anyaman, cahaya, warna dan lain-lain.

5) Menjaga agar tekstil tidak cepat rusak, baik oleh bahan kimia, gerakan mesin, temperatur cucian, dan lain-lain.

Proses/siklus operasional laundry secara lengkap adalah sebagai berikut:

1) Mengumpulkan semua linen-linen kotor dari semua outlet. Seksi yang bertugas memilahmilah semua linen yang ada kemudian petugas sebisa mungkin meletakkan linenlinen yang ada container yang terpisah untuk masing-masing jenis untuk memudahkan proses pengerjaan, sehingga pengerjaan bagian laundry lebih terfokus pada linenlinen atau pakaian-pakaian yang membutuhkan pre-treatment secepatnya.

2) Sortir: Sewaktu di ruang pencucian, linen harus dipilah-pilah sesuai jenis dan kesiapannya untuk dicuci. Karena setiap jenis pakaiaan atau linen membutuhkan temperature air dan campuran chemical yang berbeda, linen-linen harus hati-hati sebelum dimasukan pencucian.

3) Perhatian pada noda-noda: Sebelum memasukan linen-linen ke pencucian, perhatian khusus harus pada jenis noda yang sulit untuk dihilangkan sebelum merendam dan memproses lebih lanjut.

4) Memasukan: Mesin cuci dan pengering memiliki kapasitas maksimum yang diperbolehkan, seperti contohnya adalah sebuah mesin 35-pound memiliki kapasitas kain yang masuk sekitar 35-pound dari kainkain yang kering.

5) Mencuci/Memeras: Setelah memasukkan semua linen yang sudah dipilah-pilah dan diperhatikan serta yang membutuhkan perhatian khusus maka dicuci dan diperas.

6) Mengeringkan: Cucian yang sudah diperas dan menjadi lembab dipindahkan ke dalam mesin pengering yang disebut tumbler. Dalam mesin ini cucian yang lembab diberi udara panas sehingga cucian menjadi kering.

7) Menyetrika: Cucian yang sudah kering disetrika dengan mesin pres, ironer, atau flat roll ironer.

8) Melipat: Linen-linen harus dilipat secepatnya setelah pengeringan atau penyetrikaan untuk menghindari lecek.

9) Menyetor/Mendistribusikan ke Outlet masing-masing. Sewaktu linen-linen sudah dilipat dan diusahakan sebisa mungkin tidak terpegang dengan tangan terlalu sering. Linen-linen yang sudah selesai harus dikembalikan ke rak-rak yang sudah tersedia sehingga siap untuk dipakai. Begitu juga dengan pakaian milik tamu yang juga harus dikembalikan.

Setelah dari proses diatas bagian laundry harus melakukan persediaan line agar pelayanan dapat dilakukan secara akurat dan memuaskan. Linen yang diproses pada bagian laundry adalah makanan sehari-hari di dalam operasional dibagian laundry.Hal itu disebabkan karena linen adalah persediaan perlengkapan kamar atau room supplies yang dikategorikan sebagai barang persediaan yang dapat diolah/diproses kembali (Recycled Inventory Linen). Oleh karena itu perseddiaan linen berada di bawah tanggng jawab Executive Housekeeper dan biaya yang dikeluarkan untuk pengadaan dan pemeliharaan linen adalah terbesar kedua di bagian Tata Graha setelah gaji karyawan.

Kemudian selanjutnya untuk dapat menentukan jumlah persediaan linen seperti bath towel di kamar itu sendiri akan tergantung pada beberapa faktor sebagai berikut:

1) Frekuensi penggantian linen kamar. Pada umumnya hotel-hotel besar selalu mengganti setiap hari seluruh linen pada kamar-kamar. Kamar tersebut diisi sheet, towel, dan sebagainya. Oleh karena itu hotelhotel besar akan memerlukan jumlah persediaan linen kamar lebih banyak dibanding dengan hotel kecil yang tidak mengganti linen kamarnya yang diisi setiap hari.

2) Peralatan dan perlengkapan laundry. Peralatan dan perlengkapan pada bagian pencucian (laundry) akan berpengaruh terhadap jumlah persediaan linen. Makin canggih dan lengkap peralatan yang dipakai maka pelaksanaan pencucian dapat diselesaikan dengan cepat. Oleh karena itu, jumlah persediaan linen dapat lebih banyak atau tersedia dibandingkan hotel yang hanya mempunyai peralatan laundry sederhana.

3) Pemakaiaan jumlah linen setiap kamar. Hal lain yang perlu dipertimbangkan dalam menentukan jumlah persediaan linen, seperti bath towel kamar adalah jumlah setiap jenis linen yang digunakan/dipasang untuk setiap kamar.

4) Anggaran yang tersedia. Faktor yang sangat berpengaruh dalam menentukan jumlah 
persediaan linen kamar adalah anggaran yang tersedia. Berapapun jumlah persediaan linen harus disediakan, bila anggarannya tidak tersedia maka jumlah tersebut tidak terealisir (Ikhsan, 2009).

\section{h. Pelayanan Room Attendant}

Pelayanan room attendant dimulai dari membersihkan semua area, terutama di kamar tamu dimana keindahan kamar tamu terletak pada kelengkapan kamar. Kelengkapan kamar tamu dilihat dari pengadaan linen. Adapun definisi linen adalah barang-barang seperti sprei, sarung bantal, handuk, taplak meja, dan napkins. (Bagyono, 2011:96). Jenis linen supplies kamar tamu adalah:

1) Linen yang dipergunakan untuk merapihkan tempat tidur:

a) Pillowcase (sarung bantal)

b) Sheet (seprai ukuran singgle dan double)

c) Blanket (selimut)

d) Bed pad (alas di meja matras, terbuat dari linen tebal)

e) Bed skirt (penutup spring box agar terlihat rapih)

f) Bed cover atau bed spread

2) Linen supplies di kamar mandi, yaitu:
a) Bath towel (handuk badan)
b) Hand towel (handuk tangan)
c) Face towel (handuk muka)
d) Bath mat (handuk keset)
e) Shower curtain (korden penutup saat tamu mandi) (Darsono, 2011:96).
Syarat linen yang baik adalah sebagai berikut (Darsono, 2011: 98):

1) Linen-linen tidak bernoda

2) Linen-linen tidak sobek

3) Linen tidak berlubang setelah dipress

4) Linen tidak bau atau lembab

Adapun tugas dan tanggung jawab seksi linen yaitu bertanggung jawab terhadap pengadaan sirkulasi dan penggantian linen untuk keperluan tata graha, restaurant, bar, banquet, dan outlet lainnya. Kelancaran sirkulasi pemakaian linen sangat menentukan kegiatan operasional hotel.

Dalam kegiatan pengadaan linen kelancaran pengiriman linen yang kotor ke laundry atau pengiriman linen bersih dari laundry ke linen room sangat menentukan, hal ini harus didukung oleh cara penyimpanan linen yang baik dan benar selanjutnya mempunyai par stock (jumlah persediaan) tiga, empat kali.

Pelaksanaan tugas dapat berhasil karena didukung oleh bagian yang menggunakan linen dan pengontrolan linen secara teratur yang disebut dengan linen inventory yang diadakan harian, mingguan, bulanan, dan tahunan (Darsono, 2011:92). Prosedur dalam pengiriman dan pengambilan linen, yaitu:

1) Semua linen kotor dari tiap-tiap kamar dikumpulkan di roomboy station oleh roomboy. Semua linen yang kotor disortir dan dihitung, selanjutnya dikumpulkan di linen room, dari linen room semuanya dikirim ke laundry plan, dikelompokkan berdasarkan jenisnya dalam catatan linen dan laundry delivery slip.

2) Setelah dimasukkan ke laundry, kita dapat mengambil linen yang bersih sesuai dengan yang kita kirim, selanjutnya linen tersebut kita simpan di linen room. Pengambilan linen kotor dan linen bersih dilakukan oleh seorang linen runner.

\section{o. Pendistribusian Linen}

Pendistribusian linen yang berjalan di hotel merupakan serangkaian organisasi yang saling tergantung dan terlihat dalam proses untuk linen untuk siap digunakan.

Distribusi adalah serangkaian organisasi yang saling tergantung dan terlibat dalam proses untuk menjadikan suatu barang atau jasa siap untuk digunakan atau di konsumsi (Kotler, 2007 dalam Kurniati, 2013:18). Bila digambarkan pendistribusian linen dalam hotel yaitu yang kotor dikirim oleh linen runner kemudian dikirim ke laundry untuk ditukarkan dengan linen yang bersih yang akan digunakan oleh roomboy dalam membersihkan kamar.

\section{p. Persediaan Linen di Hotel}

Jumlah persediaan linen untuk operasional di hotel harus mencukupi kebutuhan. Guna mendukung operasional sehari-hari, persediaan linen harus lancar dengan jumlah persediaan memadai. Jumlah persediaan linen biasanya dinyatakan dengan istilah par stock. Jumlah linen yang memadai adalah 4 kali jumlah yang terpasang (Darsono, 2011: 98):

1) 1 par stock di kamar

2) 1 par stock dalam keadaan kotor

3) 1 par stock di linen room

4) 1 par stock di laundry

\section{Rerangka Pemikiran Penelitian}

Peneliti menganalisis SOP penyediaan bath towel yang dimiliki The Acacia Hotel Jakarta dengan membandingkan dan menganalisis komponen SOP penyedian bath towel sesuai 
dengan kajian teori yang didapat. Setelah dianalisis kemudian akan diketahui apakah SOP penyediaan bath towel sudah berjalan efektif atau belum.

Kerangka penelitian ini dapat digambarkan sebagai berikut:

\section{Gambar 1. Kerangka Pemikiran}

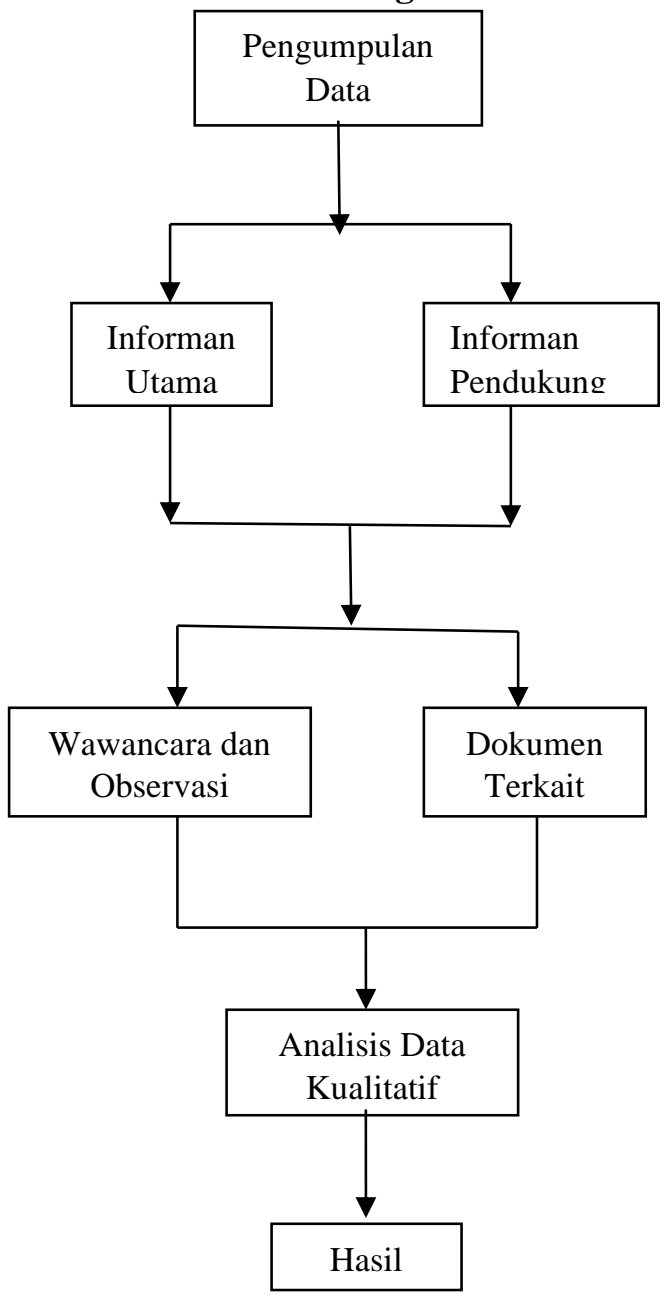

\section{METODE PENELITIAN}

Pen Penelitian ini dilakukan di The Acacia Jakarta. Populasi dalam penelitian ini adalah seluruh staff dan daily worker di Department Housekeeping The Acacia Hotel Jakarta. Sampel dalam penelitian ini adalah Executive Housekeeper, Assistant Executive Housekeeper, Supervisor, dan Room Attendant yang memiliki kemampuan dalam membina anak buahnya, serta dapat memberikan kinerja karyawan yang maksimal, dan setelah dilakukan teknik sampling menggunakan purposive sampling, didapatkan sampel sebanyak 10 orang, yang terdiri dari 1 orang informaan utama dan 9 orang informan pendukung. Adapun dalam penelitian ini, jenis pendekatan penelitian yang digunakan adalah deskriptif kualitatif.

\section{HASIL PENELITIAN}

\section{Hasil Studi Pustaka Jurnal}

Berdasarkan hasil yang didapat, peneliti menemukan kurang baiknya pendistribusian bath towel ke setiap floor section, sehingga menghambat operasional kerja room attendant dalam memenuhi kelengkapan bath towel di kamar tamu yang mengakibatkan timbulnya keluhan pada tamu ketika menginap. Hal itu disebabkan oleh mesin-mesin pencucian linen yang mengalami kerusakan, sehingga pencucian linen dilakukan di luar hotel The Acacia Jakarta. Akibatnya, terjadi kekurangan par stock persediaan bath towel yang dimiliki oleh The Acacia Hotel Jakarta, yaitu hanya 1 1/2 (satu setengah) par stock atau sebanyak 625 bath towel yang dimiliki, sedangkan seharusnya untuk memenuhi kelengkapan kamar hotel yang berjumlah 208 kamar ketika tingkat hunian tinngi kebutuhan bath towel yang dibutuhkan adalah sebanyak 3 par stock atau sebayak 1.248 bath towel.

Keadaan seperti ini sering kali terjadi ketika tingkat hunian kamar mencapai lebih dari 50\%, sehingga mengakibatkan banyaknya keluhan tamu. Hal ini juga terjadi ketika tingkat hunian kamar mencapai 80\% atau 166 kamar dan kebutuhan bath towel sebanyak 664, hotel The Acacia yang hanya memiliki 625 bath towel, sedangkan bath towel yang seharusnya diperlukan dalam satu hari adalah sebanyak 664 bath towel sebanyak 39 bath towel atau 19 kamar yang harus dilengkapi guna memenuhi kepuasan tamu yang menginap.

Pencucian bath towel yang dilakukan di luar hotel The Acacia Jakarta ini juga menimbulkan pencucian bath towel yang kurang maksimal seperti pencucian linen khususnya bath towel yang kurang bersih (spot), resiko kehilangan bath towel yang berkualitas baik dan berlogo, dan keterlambatan pengiriman bath towel yang berpengaruh terhadap service kepada tamu. Hal ini tentu sangat mempengaruhi operasional kerja housekeeping dalam usaha memberikan kepuasan pada tamu yang menginap.

Berdasarkan hasil wawancara mendalam dengan housekeeper, supervisor, room attendant, dan laundry section di Hotel The Acacia, didapatkan bahwa kerusakan pada 
mesin-mesin laundry merupakan masalah yang sangat serius dan harus segera ditangani oleh pihak perusahaan. Selain itu, permasalahan kurangnya par stock bath towel yang tidak mencapai minimal 2 par stock ini, sebaiknya memiliki minimal 3 par stock dalam satu hari operasional untuk menghadapi tingkat hunian kamar yang tinggi.

\section{a.Gambaran Penerapan SOP dalam Penyediaan Bath Towel The Acacia Hotel}

Sesuai dengan perjanjian kontrak kerja yang telah dibuat antara pihak The Acacia Hotel Jakarta baik itu pada bagian laundry section dengan outside laundry yaitu:

1) Waktu pengantaran pertama bath towel bersih dilakukan pada pukul 09.00 pagi, dimana sebelumnya pengambilan bath towel kotor (dirty linens) pada pukul 15.00 (dihari sebelumnya). Kemudian, dilakukan penghitungan jumlah bath towel yang akan dibawa oleh pihak outside laundry untuk dilakukan pencucian yang disertai dengan menyerahkan receiving and delivery of linen form oleh pihak laundry The Acacia Hotel Jakarta. Form tersebut diisi oleh laundry supervisor didalamnya terdapat jumlah bath towel kotor yang akan dibawa oleh pihak outside laundry yang berguna agar tidak terjadi ketidaksesuaian jumlah pengambilan maupun pengembalian bath towel. Selanjutnya setelah bath towel bersih diterima operasional pendistribusian bath towel ke setiap kamar segera dilakukan oleh bagian linen runer dengan menyerahkannya kepada room attendant di setiap floor sesuai dengan jumlah kebutuhan bath towel yang dibutuhkan oleh room attendant pada sectionnya tersebut.

2) Selanjutnya yaitu pihak outside laundry pada pukul 11.00-13.00 kembali melaksanakan tugasnya mengambil (pick up) linen kotor diantaranya bath towel dimana pada pukul 08.00 room attendant telah memulai tugasnya dalam membersihkan kamar tamu (make up room) dan tentunya mengganti bath towel kotor dangan bath towel bersih. Bath towel kotor segera diserahkn kepada pihak outside laundry untuk segera dilakukan pencucian, yang sebelumnya dilakukan proses penghitunngan dan serah terima bath towel oleh pihak laundry The Acacia Hotel Jakarta. Dalam hal ini laundry supervisor memberikan receiving dan delivery form, yang berisi jumlah bath towel dan harus segera dilakukan pencucian, kemudain diberikan kembali ketika proses pencucian selesai dilakukan.

3) Sesuai dengan kontrak kerja yang telah dibuat antara pihak hotel dengan pihak outside laundry, yaitu selanjutnya pada pukul 15.00 selesai proses pencucian bath towel dan pihak outside laundry segera mengantarkan linens dan bath towel kepada pihak The Acacia Hotel Jakarta. Dalam hal ini, adanya proses serah terima yang dilakukan melalui security hotel untuk dilakukan pengecekan barang yang dibawa oleh pihak outside laundry. Selanjutnya dilakukan proses serah terima bath towel (linens) antara pihak laundry The Acacia Hotel Jakarta (laundry supervisor) dengan pihak outside laundry dengan mengisi receiving and delivery form yang sebelumnya pihak outside laundry memberikan Surat Jalan Pengiriman Barang (SJPB) ke pada pihak laundry The Acacia Jakarta.

4) Par stock bath towel yang dimiliki oleh The Acacia Jakarta hanya mencapai $1 \frac{1}{2}$. Adapun apabila keadaan tingkat hunian kamar (occupancy) mencapai $80 \%$ dapat melakukan konfirmasi antara pihak laundry The Acacia Hotel Jakarta yang dalam hal ini Housekeeper dengan pihak outside laundry agar dapat dilakukan penjemputan (pick up) bath towel bersih oleh pihak housekeeping department The Acacia Hotel Jakarta ke tempat pencucian (outside laundry) guna melengkapi kekurangan bath towel pada kamar tamu yang menginap.

\section{b. Evaluasi Penerapan Standard Operasional} Procedure Housekeeping Department dalam Penyediaan Bath Towel Di The Acacia Hotel Jakarta

Berdasarkan hasil observasi dan wawancara mendalam yang telah dilakukan peneliti, berikut ini peneliti berusaha memberikan beberapa saran yang kiranya bergunan bagi peneliti dan perusahaan tempat peneliti bekerja:

1) Perbaikan mesin-mesin laundry. Perbaikan mesin laundry harus segera dilakukan, guna mengurangi dampak negatif akibat pencucian bath towel secara outsourcing diantaranya ketidakpastian kinerja pemberi jasa ternyata tidak 
memuaskan baik itu tenaga dan waktu yang diberikan

2) Penyesuaian kebutuhan par stocks bath towel. Kebutuhan bath towel yang dimiliki The Acacia Hotel Jakarta saat ini sangat jauh dari cukup, yaitu hanya 11/2 yang seharusnya kebutuhan bath towel yang dimiliki adalah 3 par stock. Apabila hal ini tidak ditanggapi dengan serius oleh pihak perusahaan akan mengakibatkan semakin banyaknya keluhan pada tamu-tamu yang menginap terutama pada saat tingkat hunian kamar hotel tinggi sehingga mengakibatkan citra hotel menjadi sangat buruk.

3) Solusi yang dilakukan Housekeeping Department The Acacia Hotel

a) Melakukan upaya permintaan pembelian bath towel melalui housekeeper untuk dilanjutkan ke purchasing department.

b) Melakukan program go green yaitu dengan tidak mengganti bath towel di kamar tamu yang apabila bath towel tersebut tidak kotor dan dalam keadaan masih tergantung di lemari atau di kamar mandi dengan memberikan selembaran pemberitahuan yang di letakan di dalam kamar yang berisikan apabila bath towel tersebut ingindi ganti silahkan menghubungi guest service center hotel.

c) Melakukan upaya peminjaman bath towel oleh pihak laundry luar hotel pada saat tingkat hunian mencapai lebih hari $50 \%$ dan dalam kondisi jumlah bath towel yang tidak memadai.

d) Memantau operasional pendistribusian bath towel dari mulai pendistribusian ke setiap kamar, pengambilan bath towel yang kotor yang ada di setiap trolly room attendant uuntuk dilakukan pencucian oleh pihak laundry luar hingga proses penerimaan bath towel yang sudah bersih, menghitung untuk selanjutnya segera di distribuusikan ke setiap kamar.

e) Mengupayakan dan mengecek pada setiap pantry dan trollyroom attendant memastikan tidak ada bath towel yang tersisa dan sudah di distribusikan ke setiap kamar tamu yang menginap.

f) Untuk kamar dengan type bed king hanya disediakan 1 bath towel saja.

Melakukan upaya pengambilan bath towel bersih kepada pihak ke 3 pada waktu yang sudah ditentukan yang sebelumnya telah membuat perjanjian antara pihak outside laundry dengan housekeeper yang mana sesuai kontrak atau perjanjian yang telah disepakati yaitu pihak ke 3 hanya mengantarkan bath towel bersih sebanyak dua kali menjadi tiga kali yang berguna melengkapi kekurangn bath towel pada saat tingkat hunian kamar mencapai $50 \%$., biasanya dilakukan pada pukul 20.00 karena proses pencucian bath towel selesai pada waktu tersebut.

\section{SIMPULAN}

Kendala yang menyebabkan terhambatnya pendistribusian bath towel ke kamar tamu adalah terbatasnya jumlah par stocks bath towel yang hanya $1 \frac{1}{2}$. Sedangkan seharusnya untuk memenuhi kelengkapan kamar hotel yang berjumlah 208 kamar ketika tingkat hunian tinngi kebutuhan bath towel yang dibutuhkan adalah sebanyak 3 par stock atau sebanyak 1.248 bath towel apabila tingkat hunian kamar mencapai $100 \%$. Keadaan seperti ini seringkali terjadi ketika tingkat hunian kamar mencapai lebih dari 50\%, sehingga mengakibatkan banyaknya keluhan tamu.

Pencucian bath towel yang dilakukan di luar hotel dikarenakan mesin-mesin laundry The Acacia Hotel Jakarta yang rusak ini juga menimbulkan pencucian bath towel yang kurang maksimal seperti pencucian linen khususnya bath towel yang kurang bersih (spot), resiko kehilangan bath towel yang berkualitas baik dan berlogo, dan keterlambatan pengiriman bath towel yang berpengaruh terhadap service kepada tamu. Hal tersebutlah yang sering kali terjadi dari kurangnya persediaan bath towel di The Acacia Hotel Jakarta. Hal ini tentu sangat mempengaruhi operasional kerja housekeeping dalam usaha memberikan kepuasan pada tamu yang menginap.

Berdasarkan hasil wawancara mengenai kurangnya persediaan bath towel di Hotel The Acacia Jakarta, ada beberapa solusi yang dapat dilakukan oleh Housekeeping Department, diantaranya:

a.Melakukan upaya permintaan pembelian bath towel melalui housekeeper, untuk dilanjutkan ke purchasing department

b. Melakukan program go green, yaitu dengan tidak mengganti bath towel di kamar tamu yang masih tergantung di lemari atau di kamar mandi

c. Melakukan upaya peminjaman bath towel oleh pihak laundry luar hotel 
pada saat tingkat hunian mencapai lebih hari $50 \%$,

d. Memantau operasional pendistribusian bath towel dari mulai pendistribusian ke setiap kamar, pengambilan bath towel yang kotor yang ada di setiap trolly room attendant untuk dilakukan pencucian oleh pihak laundry luar hingga proses penerimaan bath towel yang sudah bersih.

Mengupayakan dan mengecek pada setiap pantry dan trollyroom attendant memastikan tidak ada bath towel yang tersisa dan sudah di distribusikan ke setiap kamar tamu yang menginap, dan untuk kamar dengan type bed king hanya disediakan 1 bath towel saja..

\section{DAFTAR PUSTAKA}

Ariani, Dorothea Wahyu. 2008. Management Kualitas. Jakarta

Bagyono.2006. Manajemen Housekeeping Hotel Bandung:Alfabeta

Barutu Donna, Meri. 2009. Peranan Room Boy Pada Operasional Housekeeping DepartmentUntuk meningkatkan Pelayanan Kamar di Hotel Emerald Garden International, Medan:PT Gramedia Wirasaran Indonesia.

Bellia, Fristi. 2011. Analisis Perilaku Tidak Aman Pekerja Konstruksi PT. PP (Persero) di Proyek Pembangunan Tiffany Apartemen Jakarta Selatan Tahun 2011.

Darsono, Agustinus. 1999. Tata Graha Hotel Housekeeping, Jakarta: PT Gramedia Wirasarana Indonesia.

Chotimah, Nurul, Azkiyah. 2017. Evaluasi Sistem Pengendalian Intern Persediaan
Bahan Baku Pada PT. Mutiara Permata Bangsa.

Fauzar, Ikhsan. 2009. Kinerja Section Laundry Terhadap Tingkat Kepuasan Tamu Di Best Western Hotel Asean Internasional Medan.

Kurniati, Hikmatul. 2013. Usaha Meningkatkan Pelayanan Pengadaan Linen dan Amenities Terhadap Room Attendant Di Hotel The Acacia Jakarta.

Orbani Lutfi, Bagyono 2003. Dasar - dasar Housekeeping dan Laundry Hotel Yogyakarta:Adi Citra Karya Nusa.

Pahlevi, Fauzi. 2014. Implementasi Standard Operating Procedures (SOP) Penyelenggaraan Umrah Pada PT Tur Silaturahmi Nabi (TURSINA TOURS) Jakarta.

Purwani. 2004. Pengertian Dan Definisi hotel. Bina Karya. Jakarta.

Pangabean Roni, Prima. 2009. Peranan Room Attendant Dalam Meningkatkan Mutu Pelayanan. Yogyakarta.

Rumekso. 2001. Housekeeping Hotel. Andi. Yogyakarta.

Safitri, Ellis. 2016. Peranan Room Attendant Dalam Meningkatkan Kualitas Pelayanan Kamar Di Hotel The Acacia Jakarta

Suryanata Agus, I Putu. 2016. Upaya Laundy Section Dalam Menangani Kehilangan dan Kerusakan Linen Guest Room di Sanur Paradise Plaza Hotel

Wijaya, Niko. 2014. Prosedur Penanganan Keluhan Pelanggan Pada PT Pos Indonesia Cabang Palembang.

Wojowasito, S, W.J.S. Poerwodarminto. 1980. Kamus Lengkap Inggris-Indonesia, Indonesia-Inggris, dengan Ejaan yang Disempurnakan, Bandung:Hasta. 